\title{
Elevated Endostatin Expression Is Regulated by the plgA Immune Complex and Associated with Disease Severity of IgA Nephropathy
}

\author{
Yaling Zhai Xiaoqing Long Jingge Gao Xingchen Yao Xinnian Wang \\ Zhanzheng Zhao \\ Department of Nephrology, The First Affiliated Hospital of Zhengzhou University, The Renal Research Institution of \\ Zhengzhou University, Zhengzhou, China
}

\section{Keywords}

$\lg$ A nephropathy $\cdot$ plgA immune complex $\cdot$ Endostatin

\begin{abstract}
Background/Aims: Renal vascular injury accounts for the poor outcomes of patients with IgA nephropathy (IgAN). In this study, we investigated whether endostatin, a potent inhibitor of angiogenesis, is associated with IgAN. Methods: Serum endostatin levels were detected in patients with $\lg \mathrm{AN}$, disease controls, and healthy controls, and the correlation among endostatin and clinicopathologic manifestations, as well as prognosis in patients with IgAN, was analyzed. In addition, serum endostatin levels were compared in patients "before" and "after" treatment. Data on endostatin expression in the renal interstitium of patients with IgAN were downloaded and analyzed from the GSE35489 array in the GEO database. The poly-lgA1 (plgA) immune complex is widely recognized as the "trigger" of IgAN initiation. plgA in the plasma of patients was extracted and used to stimulate human glomerular endothelial cells (GECs). Endostatin, IL-6, and CXCL1 in the cell supernatant were detected by ELISA kits. Results: We found that serum endostatin levels were significantly increased in patients with $\lg A N$, as
\end{abstract}

karger@karger.com www.karger.com/kbr

Karger $\stackrel{\text { ' }}{5}$

GOPEN ACCESS
(C) 2020 The Author(s)

Published by S. Karger AG, Basel

This article is licensed under the Creative Commons AttributionNonCommercial-NoDerivatives 4.0 International License (CC BYNC-ND) (http://www.karger.com/Services/OpenAccessLicense) Usage and distribution for commercial purposes as well as any distribution of modified material requires written permission. was endostatin expression in the renal interstitium. Patients with IgAN were divided into 2 groups according to the median value. The high endostatin expression group had significantly higher levels of serum creatinine and BUN and more severe tubular/interstitial damage. Moreover, patients with arteriolar injury and endothelial cell proliferation had higher serum endostatin levels. Patients with high serum endostatin levels had poor prognosis. According to the in vitro experiment, the GEC apoptosis rate and the supernatant levels of endostatin, IL-6, and CXCL1 were significantly increased following plgA stimulation. Conclusion: Our study found that elevated endostatin expression was associated with disease severity and poor prognosis in patients with IgAN and can be upregulated by plgA, but how it participates in the pathogenesis of IgAN deserves further exploration.

(c) 2020 The Author(s).

Published by S. Karger AG, Basel

\section{Introduction}

IgA nephropathy (IgAN) is the most common primary glomerulonephritis worldwide [1]. The lack of effective treatment makes it an important disease leading to ESRD, 
and it brings heavy economic and spiritual burdens to the society and the family. The pathogenesis of IgAN is very complex and still unclear. The deposition of poly-IgA1 (pIgA) immune complexes in the glomeruli is widely recognized as the "trigger"; pIgA can induce a series of "cascade reactions" and lead to renal tubular/interstitial fibrosis [2-4], a common result of renal dysfunction, indicating that circulating pIgA plays an important role in the initiation of injury in IgAN [5]. Endothelial cells are the first cells to be exposed to damage induced by pIgA. Recently, Kusano et al. [6] reported that the loss of endothelial cells may contribute to renal tubular atrophy/interstitial fibrosis in IgAN.

We found in previous studies that endothelial injury is very common in IgAN and is related to disease severity and disease prognosis [6-8]. Endothelial dysfunction, which is observed in a considerable proportion of patients with IgAN, is one of the various manifestations [9]. Our previous research found that soluble FMS-like tyrosine kinase (sFlt-1) is related to the disease severity of IgAN [10], proving that endothelial injury is related to IgAN. In addition to sFlt-1, other factors also participate in endothelial injury.

Endostatin is an endogenous angiogenesis inhibitor with a broad spectrum of antitumor activities [11-13]. It is a $20-\mathrm{kDa}$ fragment of collagen XVIII, which is a ubiquitous component of basement membranes in renal glomeruli and peritubular capillaries $[14,15]$. A recent study showed that endostatin was related to renal fibrosis in aged patients [16-18]. As renal tubular atrophy/interstitial fibrosis is also very important for IgAN, we aimed to explore whether endostatin contributes to the disease severity of IgAN and whether it is related to pIgA, a "trigger" of IgAN.

\section{Methods}

\section{Study Population and Sample Collection}

One hundred eighty patients with primary IgAN and 41 ageand sex-matched healthy controls, as well as 33 disease controls ( 9 with diabetic nephropathy, 9 with minimal change disease, 10 with focal segmental glomerular sclerosis, and 5 with membranous nephropathy), were recruited from the First Affiliated Hospital of Zhengzhou University between January 1, 2017, and December 1, 2017. Among the 180 patients with IgAN, 145 had been followed up for $>1$ month, and composite endpoint events were reached if any one of the following was met: (1) eGFR decreased $>30 \%$ from baseline or eGFR $<15 \mathrm{~mL} / \mathrm{min}$ per $1.73 \mathrm{~m}^{2}$; (2) serum creatinine doubled; (3) renal replacement therapy was needed; or (4) death. Another 18 patients with primary IgAN whose serum was available "before" and "after" treatment were included in the study from the same hospital. They were divided into 2 groups: "with remission" or "no remission." Remission was defined as a decrease in 24-h proteinuria of $30 \%$ or more or reaching $0.15 \mathrm{~g} /$ day or less with stable serum $\mathrm{Cr}$ (no $>25 \%$ increase from baseline). Patients who did not achieve remission were named the "no remission" group.

The diagnosis of primary IgAN was based on dominant IgA deposition in the mesangium by immunofluorescence and was confirmed by light microscopy and electronic microscopy at the same time. The exclusion criteria were as follows: (1) patients had been treated with a glucocorticoid or an immunosuppressor; (2) patients with secondary IgAN, such as Henoch-Schönlein purpura and liver cirrhosis, were excluded after careful examination; (3) patients with any kind of cancer or tumor; and (4) the number of glomeruli was $<10$. Clinical information, including 24 -h urine protein excretion and hemoglobin, was collected from medical records. Oxford classification was used to score the pathological change by 2 pathologists $[3,4]$ who were both blinded to the clinical data.

After the consent form was signed, $10 \mathrm{~mL}$ of venous blood was collected in the morning of the day during which a renal biopsy was performed on the patients or on the day the healthy controls were recruited. The serum was separated from whole blood, divided into aliquots, and stored at $-80^{\circ} \mathrm{C}$ for the subsequent measurement of endostatin.

The Medical Ethics Committee of the First Affiliated Hospital of Zhengzhou University approved the study protocol, and informed written consent was obtained from each participant. All methods reported here were carried out in accordance with relevant guidelines and regulations of the First Affiliated Hospital of Zhengzhou University.

\section{Detection of the Serum Endostatin Level}

A commercial ELISA kit was used to detect the serum endostatin level in patients with IgAN and controls according to the manufacturer's specifications (R\&D Systems, Minneapolis, MN, USA).

\section{Tubular/Interstitial Expression of Endostatin}

The mRNA expression of COL18A1, the endostatin-encoding gene, was extracted from the GSE35489 mRNA array, which was downloaded from the GEO database (https://www.ncbi.nlm.nih. gov/geo/).

\section{Isolation of the pIgA Immune Complex}

The pIgA immune complex was isolated from the mixed venous blood of 10 patients with primary IgAN using a previously described method [19]. In brief, total IgA1 was purified from the plasma with an agarose-bound jacalin affinity chromatography column (Pierce Chemical Co., Rockford, IL, USA) and then applied to a Sephacryl S-300 gel filtration chromatography column (GE Healthcare Life Sciences, Uppsala, Sweden). The fraction was pooled and concentrated at $280 \mathrm{~nm}$, which corresponded to the peak representing the $\mathrm{PIgA} 1$ complex. After identification by Western blotting and ELISA, the pIgA immune complex was frozen at $-80^{\circ} \mathrm{C}$ for the subsequent experiment.

\section{Human GEC Culture and Treatment}

Human renal glomerular endothelial cells (GECs) (ScienCell, Carlsbad, CA, USA) were cultured according to the manufacturer's specifications in the endothelial cell medium supplemented with endothelial cell growth supplement, $5 \%$ fetal bovine serum, 
Table 1. Baseline data of enrolled IgAN patients and healthy controls

\begin{tabular}{|c|c|c|}
\hline \multirow[t]{2}{*}{ Characters } & \multicolumn{2}{|c|}{ Mean \pm SD or median $(25 \%, 75 \%)$ or $n(\%)$} \\
\hline & IgAN patients & healthy controls \\
\hline \multicolumn{3}{|l|}{ Clinical presentation } \\
\hline Male, $n(\%)$ & $104(57.78)$ & $23(56.10)$ \\
\hline Age, mean $\pm \mathrm{SD}$ & $36.19 \pm 13.30$ & $33.98 \pm 15.37$ \\
\hline \multicolumn{3}{|l|}{ Hypertension, $n(\%)$} \\
\hline With hypertension & $80(44.44)$ & \\
\hline 24-h proteinuria, g/day & $2.05(0.96,4.68)$ & \\
\hline Serum creatinine, $\mu \mathrm{mol} / \mathrm{L}$ & $93(69.50,157.50)$ & \\
\hline $\mathrm{BUN}, \mathrm{mmol} / \mathrm{L}$ & $6.50(4.80,9.30)$ & \\
\hline Uric acid, mmol/L & $376.97 \pm 110.39$ & \\
\hline $\mathrm{TCHO}, \mathrm{mmol} / \mathrm{L}$ & $4.68(3.85,5.88)$ & \\
\hline $\mathrm{TG}, \mathrm{mmol} / \mathrm{L}$ & $1.58(1.04,2.24)$ & \\
\hline Urine red blood cell, $n / \mathrm{HP}$ & $37(9,140.50)$ & \\
\hline \multicolumn{3}{|l|}{ Pathological presentation } \\
\hline \multicolumn{3}{|l|}{ Oxford classification, $n(\%)$} \\
\hline M score (M1) & $44(24.44)$ & \\
\hline E score $(\mathrm{E} 1)$ & $48(26.67)$ & \\
\hline S score (S1) & $127(70.55)$ & \\
\hline T score (T0/T1/T2) & $99(55) / 25(13.89) / 56(31.11)$ & \\
\hline C score $(\mathrm{c} 0 / \mathrm{c} 1 / \mathrm{c} 2)$ & $105(58.33) / 67(37.22) / 8(4.45)$ & \\
\hline Arteriolar injury, $n(\%)$ & $124(68.89)$ & \\
\hline Ratio of global sclerosis & $0.17(0.03,0.41)$ & \\
\hline Ratio of segmental sclerosis & $0.05(0,0.12)$ & \\
\hline
\end{tabular}

penicillin $\mathrm{G}(100 \mathrm{U} / \mathrm{mL})$, and streptomycin $(100 \mathrm{U} / \mathrm{mL})$ at $37^{\circ} \mathrm{C}$ and 5\% carbon dioxide. The cells were passaged for 3-7 generations before starting the treatment.

After $12 \mathrm{~h}$ of serum starvation, GECs were treated with $200 \mu \mathrm{g} /$ $\mathrm{mL}$ pIgA complex (after the concentrations of 50, 100, 200, and $400 \mu \mathrm{g} / \mathrm{mL}$ were explored) from patients and healthy controls for $24 \mathrm{~h}$. The supernatant was collected for endostatin, IL-6, and CXCL1 detection, and the cells were collected for proliferation activity detection.

\section{Detection of GEC Proliferation Activity}

A CCK8 kit (Genview, Beijing, China) was used for the detection of GEC proliferation activity according to the manufacturer's instructions.

Endostatin, IL-6, and CXCL1 Levels Were Detected in the Cell Culture Supernatant by ELISA

For the detection of endostatin, IL-6, and CXCL1 levels in the cell culture supernatant, standard sandwich ELISA assays were performed using commercial human endostatin, IL-6, and CXCL1 ELISA kits (all of them were purchased from R\&D Systems, Minneapolis, MN, USA) according to the manufacturer's specifications.

Statistical Analysis

Statistical analyses were performed by SPSS 22.0 software (SPSS, Inc., Chicago, IL, USA). Continuous variables were compared by the independent samples $t$ test or 1-way ANOVA between groups or by the Mann-Whitney $U$ test. Dichotomous and poly- chromous data were analyzed by the $\chi^{2}$ test. K-M curve and logrank test were used for the prognosis analysis. The results are expressed as mean \pm SD if the data were distributed normally, while other data are expressed as median (IQR). A $p$ value $<0.05$ was considered statistically significant.

\section{Results}

\section{Clinical and Pathological Manifestations of Patients with IgAN}

Our study enrolled a total of 180 patients with IgAN. The primary clinical and pathological manifestations of the patients are summarized in Table 1 . Within the 180 patients with IgAN, 104 patients were male and 76 patients were female. The average age at renal biopsy was $36.19 \pm 13.30$ years, and $80(44.44 \%)$ patients presented with hypertension. The 24 -h urine protein level was 2.05 $(0.96,4.68) \mathrm{g} /$ day. The serum creatinine level in this group was $93(69.50,157.50) \mu \mathrm{mol} / \mathrm{L}$. The serum BUN level in this group was $6.50(4.80,9.30) \mathrm{mmol} / \mathrm{L}$. The uric acid level in this group was $376.97 \pm 110.39 \mathrm{mmol} / \mathrm{L}$. The serum TCHO level in this group was $4.68(3.85,5.88)$ $\mathrm{mmol} / \mathrm{L}$. The serum TG level in this group was 1.58 $(1.04,2.24) \mathrm{mmol} / \mathrm{L}$, and the urine red blood cell count 


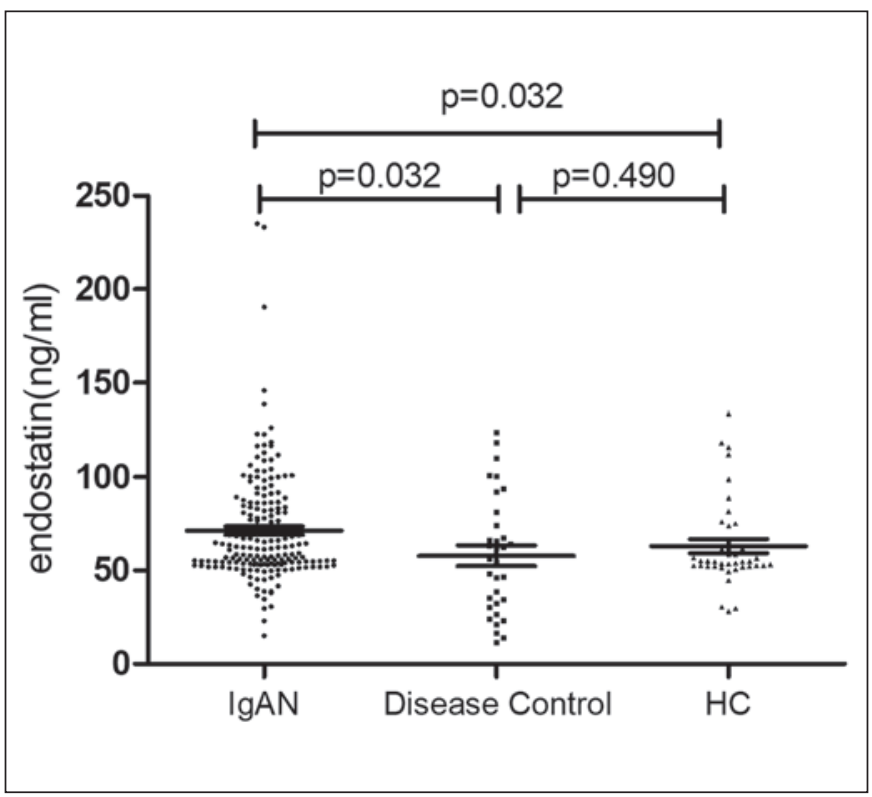

Fig. 1. Elevated serum endostatin levels in patients with IgAN. Serum endostatin levels were significantly increased in patients with IgAN compared with healthy controls $(61.71$ [53.42, 85.72] vs. $54.69[52.23,69.03] \mathrm{ng} / \mathrm{mL}, p=0.032)$ and disease controls $(61.71$ $[53.42,85.72]$ vs. $56.21[31.36,77.73] \mathrm{ng} / \mathrm{mL}, p=0.032)$. IgAN, IgA nephropathy.

in this group was $37(9,140.50) / \mathrm{HP}$. According to the Oxford classification, $44(24.44 \%)$ patients were in grade M1, 48 (26.67\%) were grade E1, 127 (70.55\%) were grade S1, 99 (55\%) were grade T1, 25 (13.89\%) were grade T2, 105 (58.33\%) were grade $\mathrm{C} 1$, and $67(37.22 \%)$ were grade C2. A total of $124(68.89 \%)$ patients had arteriolar injury in the renal interstitium. The mean ratio of global sclerosis was $0.17(0.03,0.41)$, and the mean ratio of segmental sclerosis was $0.05(0.0,0.12)$.

Serum Levels of Endostatin in Patients with IgAN

Serum endostatin levels were significantly increased in patients with IgAN compared with healthy controls $(61.71[53.42,85.72]$ vs. $54.69[52.23,69.03] \mathrm{ng} / \mathrm{mL}, p=$ $0.032)$ and disease controls $(61.71[53.42,85.72]$ vs. 56.21 $[31.36,77.73] \mathrm{ng} / \mathrm{mL}, p=0.032)$, as shown in Figure 1 .

Correlations between the Serum Levels of Endostatin and the Clinical as well as Pathological Characteristics of Patients with IgAN

The patients with IgAN were divided into 2 groups according to the median endostatin level $(61.71 \mathrm{ng} / \mathrm{mL})$, and we found significantly elevated serum creatinine and
BUN levels in the high endostatin group compared with those in the low endostatin group (serum creatine: 115 $[77,207]$ vs. $82.50[63,117] \mu \mathrm{mol} / \mathrm{L}, p=0.001$; serum BUN: $7.39[5.18,11.45]$ vs. $6.20[4.10,8.60] \mu \mathrm{mol} / \mathrm{L}, p=$ 0.024; shown in Figure 2a, b). As tubular/interstitial damage was more severe, serum endostatin was higher (T0 vs. T1: $66.52 \pm 26.63$ vs. $70.28 \pm 24.49 \mathrm{ng} / \mathrm{mL}, p=0.096$; $\mathrm{T} 1$ vs. T2: $70.28 \pm 24.49$ vs. $80.41 \pm 36.33 \mathrm{ng} / \mathrm{mL}, p=0.474$; T0 vs. T2: $66.52 \pm 26.63$ vs. $80.41 \pm 36.33 \mathrm{ng} / \mathrm{mL}, p=0.002$; shown in Fig. 2c). Furthermore, patients with endothelial cell proliferation and arteriolar injury had significantly elevated levels of serum endostatin (E1 vs. E0: $76.35 \pm$ 30.21 vs. $69.55 \pm 30.13 \mathrm{ng} / \mathrm{mL}, p=0.047$; $\mathrm{A} 1$ vs. $\mathrm{A} 0: 74.59$ \pm 33.27 vs. $64.23 \pm 20.49 \mathrm{ng} / \mathrm{mL}, p=0.026$; shown in Fig. 2d, e).

Trends in Serum Endostatin Levels after Treatment

After at least 3 months of treatment according to the KDIGO guidelines, 10 patients were divided into the "with remission" group and 8 into the "no remission" group. We detected the serum endostatin levels before treatment (on the day of renal biopsy) and after treatment and found that most patients with remission had a tendency toward a decrease although significance was not reached (Fig. 3a); however, serum endostatin levels in patients with "no remission" showed a significant increase ( $31.43 \pm 13.6$ vs. $63.71 \pm 20.58, p=0.029$; Fig. $3 b)$.

\section{Patients with High Serum Endostatin Levels Had \\ Poorer Prognosis}

A total of 145 of 180 patients with IgAN had been followed up for $>1$ month, and the median follow-up time was 16 (7.5-26.5) months. According to the mean value $(71.36 \mathrm{ng} / \mathrm{mL})$ of serum endostatin levels, patients were divided into the "high group" and the "low group," and we found that patients with high endostatin levels had poorer prognosis (log-rank test, $p=0.040$, Fig. 4).

Identification of Elevated COL18A1 Expression in the Renal Interstitium of Patients with IgAN

Endostatin is a $20-\mathrm{kDa}$ C-terminal fragment derived from type XVIII collagen (COL18A1) [20, 21], and its expression in the renal interstitium can be represented by the level of COL18A1 in the GSE35489 mRNA array. We found that COL18A1 expression was significantly different in patients with IgAN (IgAN vs. HC: GL96: $7.78 \pm$ 0.36 vs. $7.30 \pm 0.25, p=0.007$; GL14663: $7.61 \pm 0.32$ vs. $7.18 \pm 0.17, p=0.001$ ), as shown in Figure $5 \mathrm{a}$ and $\mathrm{b}$, respectively, further indicating the association between endostatin and IgAN. 
a

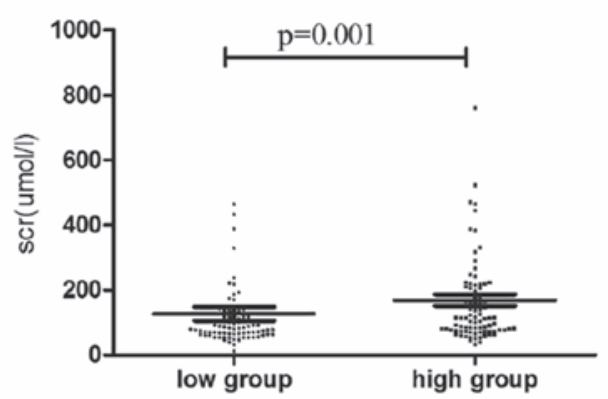

C
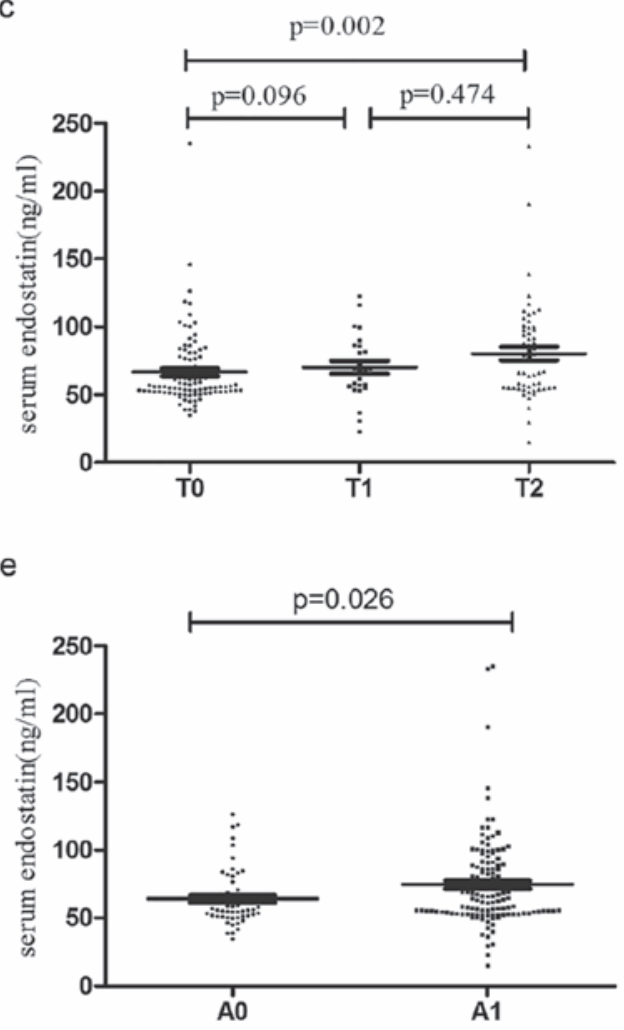

b

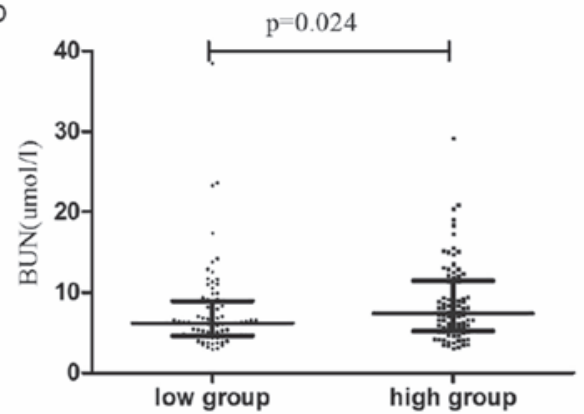

d

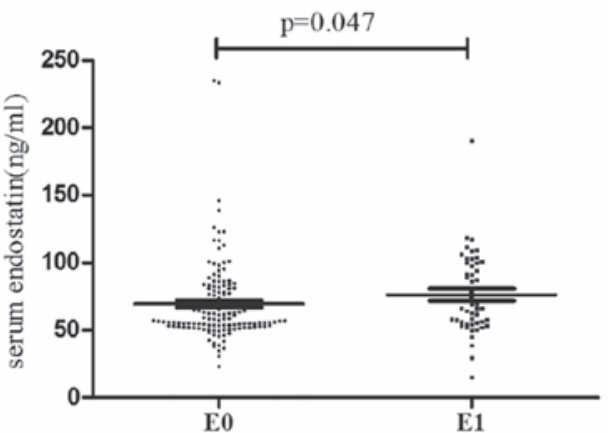

Fig. 2. The association between serum endostatin levels and clinical and pathological manifestations. Serum creatinine (a) and BUN (b) levels in the high endostatin group were significantly elevated compared with those in the low endostatin group (serum creatine: $115[77,207]$ vs. $82.50[63,117] \mu \mathrm{mol} / \mathrm{L}, p=0.001$; serum BUN: 7.39 $[5.18,11.45]$ vs. $6.20[4.10,8.60] \mu \mathrm{mol} / \mathrm{L}, p=0.024) . \mathrm{C}$ As the tubular/interstitial damage was more severe, serum endostatin was higher (T0 vs. T1: $66.52 \pm 26.63$ vs. $70.28 \pm 24.49 \mathrm{ng} / \mathrm{mL}, p=0.096$; T1 vs. T2: $70.28 \pm 24.49$ vs. $80.41 \pm 36.33 \mathrm{ng} / \mathrm{mL}, p=0.474$; T0 vs. T2: $66.52 \pm 26.63$ vs. $80.41 \pm 36.33 \mathrm{ng} / \mathrm{mL}, p=0.002)$. Furthermore, patients with endothelial cell proliferation (d) and arteriolar injury (e) had significantly elevated levels of serum endostatin (E1 vs. E0: $76.35 \pm 30.21$ vs. $69.55 \pm 30.13 \mathrm{ng} / \mathrm{mL}, p=0.047$; A1 vs. A0: $74.59 \pm 33.27$ vs. $64.23 \pm 20.49$ $\mathrm{ng} / \mathrm{mL}, p=0.026$ ). A1, with arteriolar injury; A0, without arteriolar injury; E1, with endothelial cell proliferation; E0, without endothelial cell proliferation. 


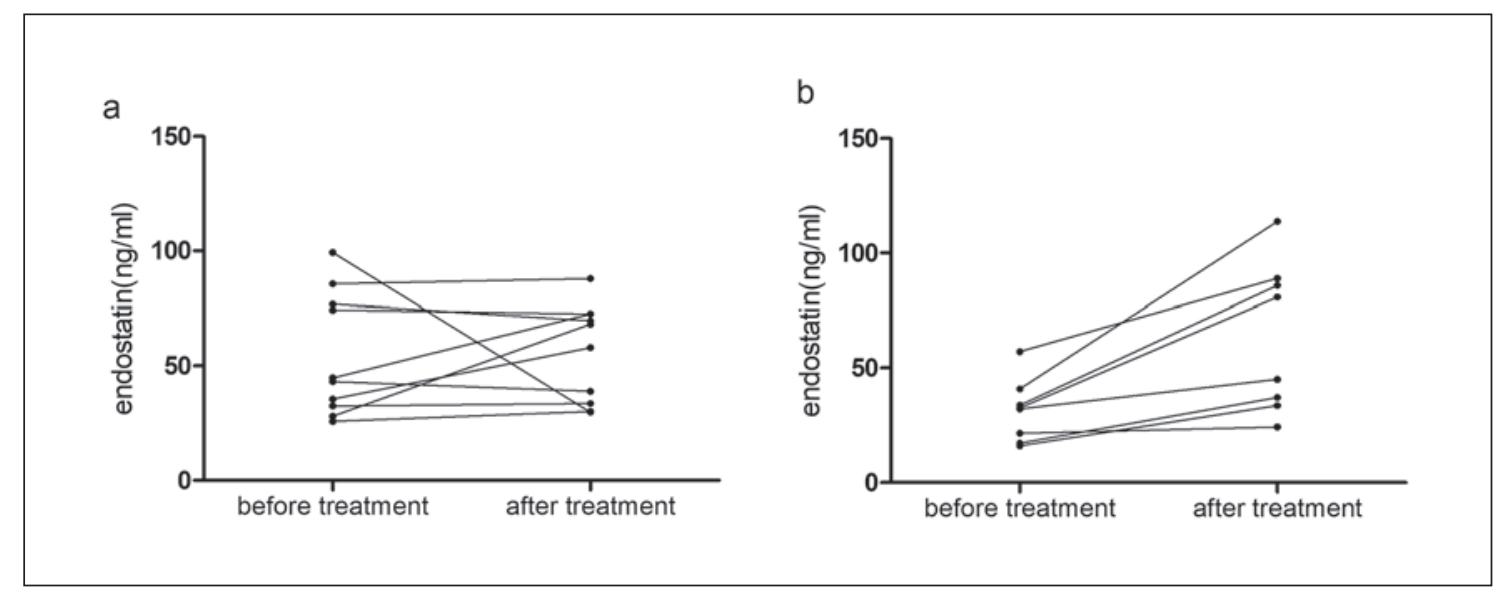

Fig. 3. Trends in serum endostatin levels after treatment. a Most patients with IgAN in the "with remission" group had a tendency toward a decrease although significance was not reached. b However, serum endostatin levels in patients with "no remission" showed a significant increase $(31.43 \pm 13.6$ vs. $63.71 \pm 20.58, p=0.029)$. $\operatorname{IgAN}, \operatorname{IgA}$ nephropathy.

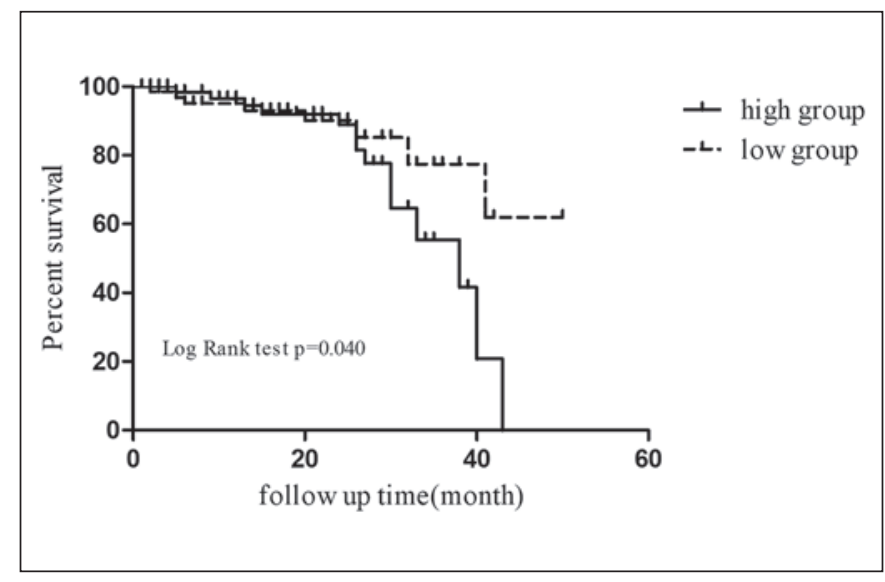

Fig. 4. Patients with high serum endostatin levels had poorer prognosis. Patients with high endostatin levels had poorer prognosis (log-rank test, $p=0.040$ ).

Increased Endostatin Expression in the Supernatant after GECs Were Stimulated with the PIgA Immune Complex

After stimulation with the pIgA immune complex, we found that endostatin expression in the supernatant was significantly increased compared with that in the control group, which was stimulated with PBS instead (pIgA vs. control: $11.75 \pm 0.66$ vs. $8.61 \pm 0.85 \mathrm{ng} / \mathrm{mL}, p=0.007$; shown in Fig. 6a).

\section{Decreased Cell Proliferation Activity and Increased} Inflammatory Factor Secretion after GECs Were Stimulated with the PIgA Immune Complex

To reveal more clues about endostatin and IgAN, we also detected the GEC proliferation activity and inflammatory factors following pIgA immune complex stimulation, and our results showed that GEC proliferation activity significantly decreased (pIgA vs. control: $0.59 \pm 0.16$ vs. $1.06 \pm 0.13, p=0.017$; shown in Fig. $6 \mathrm{~b}$ ) and that supernatant IL-6 and CXCL1 levels significantly increased (IL-6: pIgA vs. control: $1,362.19 \pm 65.29$ vs. $1,034.54 \pm$ $61.69 \mathrm{pg} / \mathrm{mL}, p=0.003$; CXCL1: pIgA vs. control: $160,833.57 \pm 8,772.20$ vs. $12,273.40 \pm 2,245.10 \mathrm{pg} / \mathrm{mL}$, $p=0.001$; shown in Fig. $6 c, d)$.

\section{Discussion}

IgAN is a common, complex disease with variable manifestations. Endothelial dysfunction is commonly observed in patients with IgAN $[8,19,20]$. Our study indicated that elevated serum endostatin levels were associated with the disease severity and prognosis of IgAN and could be upregulated by the pIgA immune complex.

Endostatin is a natural C-terminal fragment of $20 \mathrm{kDa}$ and is encoded by COL18A1[21, 22]. It is reported to be a potent antiangiogenic protein that is able to inhibit angiogenesis and tumor growth [23]. However, a recent study revealed that in the elderly, it was associated with kidney interstitial fibrosis [16], which always occurs in 


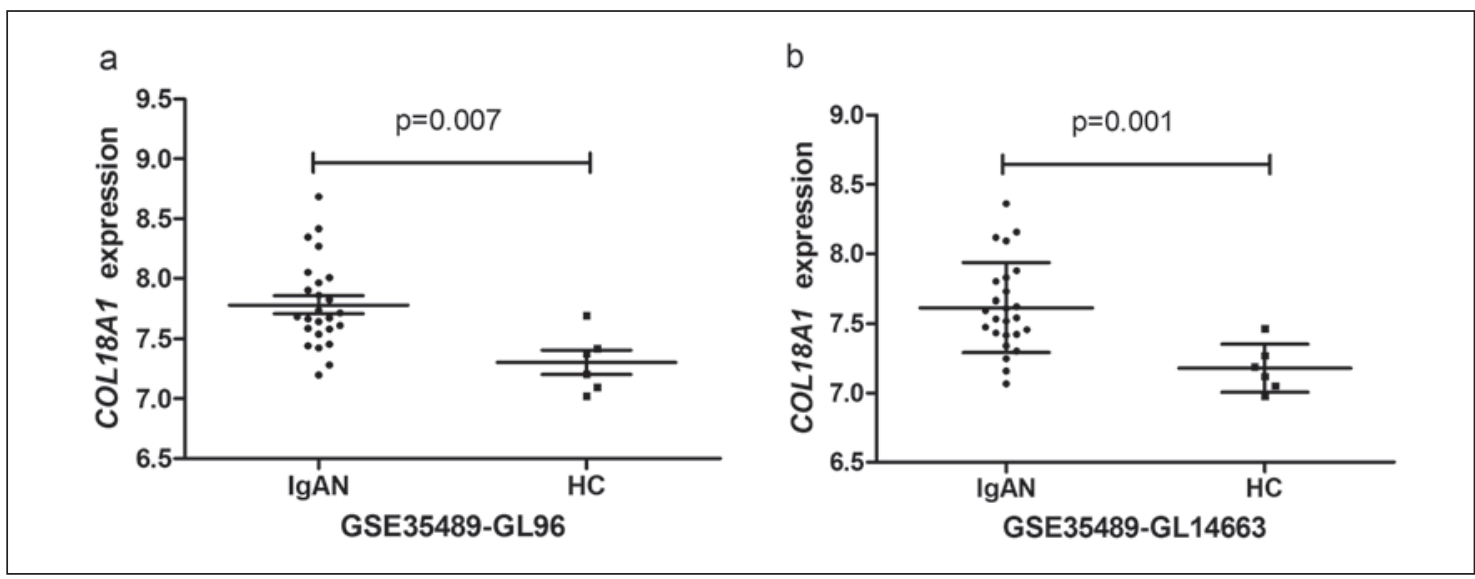

Fig. 5. COL18A1 expression in the renal interstitium of patients with IgAN in the GSE35489 mRNA array. COL18A1 expression was significantly different in the renal interstitium of patients with IgAN (IgAN vs. HC: GL96: $7.78 \pm 0.36$ vs. $7.30 \pm 0.25, p=0.007$ (a); GL14663: $7.61 \pm 0.32$ vs. $7.18 \pm 0.17, p=0.001$ (b). IgAN, IgA nephropathy.

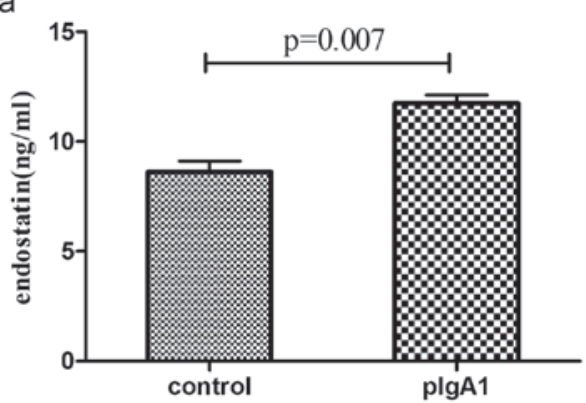

C

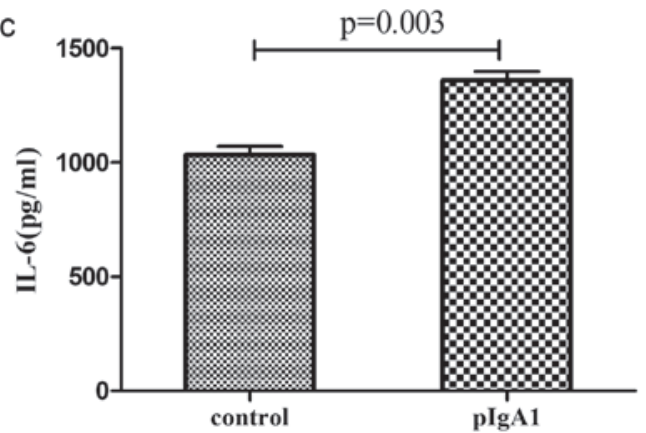

b

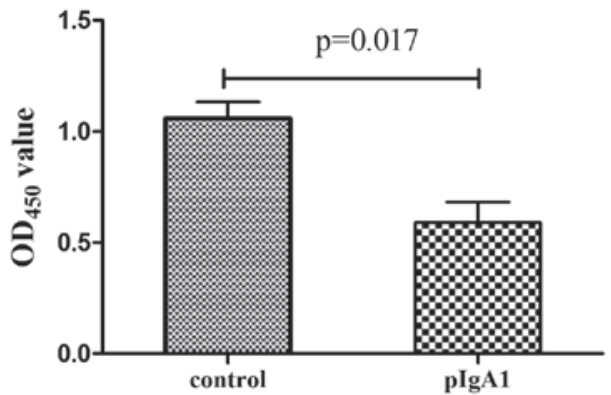

d

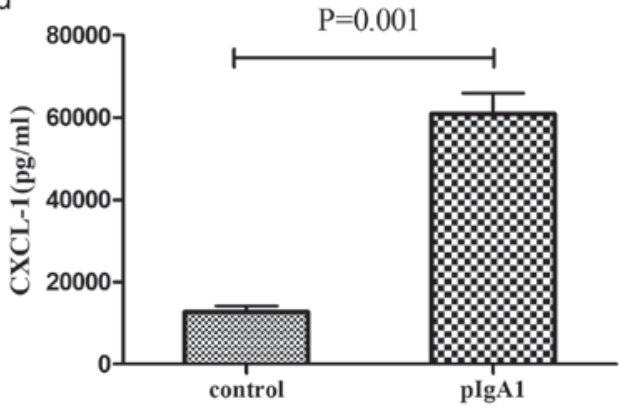

Fig. 6. The increased endostatin expression and cell apoptosis rate as well as inflammatory factor levels of GECs after pIgA stimulation. a After stimulation with the pIgA immune complex, endostatin expression in the supernatant was significantly increased compared with that of the control group, which was treated with PBS instead (pIgA vs. control: $11.75 \pm 0.66$ vs. $8.61 \pm 0.85 \mathrm{ng} / \mathrm{mL}, p=0.007$ ). $\mathbf{b}$ At the same time, GEC proliferation activity was significantly decreased (pIgA vs. control: $0.59 \pm 0.16$ vs. $1.06 \pm 0.13, p=0.017$ ), and supernatant IL-6 (c) and CXCL1 (d) levels were significantly increased (IL-6: pIgA vs. control: 1,362.19 \pm 65.29 vs. 1,034.54 \pm 61.69 pg/ $\mathrm{mL}, p=0.003$; CXCL1: pIgA vs. control: $160,833.57 \pm 8,772.20$ vs. $12,273.40 \pm 2,245.10 \mathrm{pg} / \mathrm{mL}, p=0.001)$. GEC, glomerular endothelial cell; pIgA, poly-IgA. 
$\mathrm{CKD}$ and indicates a poor prognosis. As an antiangiogenesis factor, there is no report about whether endostatin is associated with IgAN. We found in our study that the serum endostatin level in patients with IgAN was significantly higher than that in patients with CKD in another study [24]. The mean level of endostatin in healthy controls was comparable with 2 large cohorts [18], but endostatin levels in patients with IgAN were significantly lower than those in patients undergoing hemodialysis $(254.3 \mathrm{ng} / \mathrm{mL})[22]$ and slightly higher than those in renal cell carcinoma and systemic lupus erythematosus [25, 26], possibly because vascular injury was more severe in patients with hemodialysis and different ELISA kits were used in different races in the studies. Moreover, serum endostatin levels in patients with IgAN were significantly increased compared with disease controls (diabetic nephropathy, minimal change disease, focal segmental glomerular sclerosis, and membranous nephropathy were included) in this study, and there was no significant difference between disease controls and healthy controls, indicating that vascular injury in patients with IgAN was more severe than most kinds of glomerular disease. We also compared urine endostatin levels in patients with IgAN with healthy controls and found that it increased in patients although a significant difference was not reached $(p=0.074)$.

Furthermore, we explored the relationship between elevated endostatin expression and the clinical and pathological data in patients with IgAN (e.g., creatinine level, BUN level, proteinuria, and Oxford classification score). According to the results, serum creatinine and BUN levels were higher in patients with high endostatin expression, and more severe renal tubule/interstitial damage, renal arteriole injury, and GEC proliferation were also noted in these patients. This discovery indicates that endostatin was associated with the disease severity of IgAN. However, compared with a nonsignificant change in serum endostatin levels in patients with effective treatment, a significant increase was observed in patients with no response to treatment, indicating that a persistent increase in serum endostatin levels may be a biomarker for poor response to treatment. We also found that the expression of the endostatin-encoding gene COL18A1 was increased significantly in the renal interstitium of 2 independent cohorts of IgAN in the mRNA array, which further suggests that endostatin may play a certain role in patients with IgAN, which was proven by our result that patients with IgAN with high serum endostatin levels had a poorer prognosis; unfortunately, endostatin was not an independent risk factor after adjustment.
According to a previous study, the mainstream doctrine of the IgAN mechanism research is the "four-hit theory" [27]. Circulating pIgA deposition in the mesangial area and endocapillary wall is the key step leading to subsequent damage, such as endocapillary cell proliferation, arteriolar injury, and tubular atrophy/interstitial fibrosis. To further investigate the relationship between the pIgA immune complex and endostatin in patients with IgAN, we carried out an in vitro experiment and found that pIgA could stimulate GECs to secrete more endostatin, and the GEC apoptosis rate increased at the same time, indicating that the balance of angiogenesis was disturbed. IL-6 and CXCL1, well-known proinflammatory factors [28], were upregulated in GECs after pIgA stimulation in our study. According to a previous study, monocyte-macrophage infiltration is responsible for renal interstitial fibrosis, and the inflammatory factors (such as IL-6 and CXCL1) secreted by these cells could induce renal tubular epithelial cell transdifferentiation, which is the key step in renal interstitial fibrosis [29]. These inflammatory factors could be the "messenger molecules" that promote the "cross-talk" between different renal cells and may finally lead to renal dysfunction [30]. However, it is important to note that IL- 6 and CXCL1 were secreted by the injured GECs in our study, which was consistent with a recent report that endothelial cells could produce potent proinflammatory cytokines, such as IL-6, in an in vitro model of lupus nephritis [31]. A study by Tanabe et al. [32] showed that endostatin could inhibit monocyte/ macrophage accumulation, decrease the number of CD31(+) blood vessels, and alleviate peritoneal fibrosis in a peritoneal dialysis mouse model. Additionally, another study proved that higher cathepsin S, which modulates the antiangiogenic activities of human endostatin [33], was associated with higher CRP and IL-6 levels [34], providing us with a bold speculation - whether the possibility exists that IL- 6 and CXCL1 secretion by GECs may be regulated by endostatin, which was upregulated by pIgA.

Notably, our present study had disadvantages. First, it was a retrospective study. Second, we did not extract pIgA separately from each patient because of its very small amount in human serum, and the extraction process is very complex. Third, our study only observed a relationship between endostatin and IgAN; however, how endostatin participates in the pathogenesis of IgAN is still unclear.

A prospective design would have probably helped to understand more about the pathogenetic role of endostatin and could have provided more exact information on the effect of the therapy on endostatin. In addition,
38

Kidney Blood Press Res 2021;46:31-40 DOI: $10.1159 / 000508079$
Zhai et al. 
exploration of the pathogenesis of endostatin involvement in IgAN needs to be conducted.

In conclusion, the present study found that elevated endostatin expression in patients with IgAN was correlated with clinical and pathological manifestations, as well as prognosis, which provides the possibility of endostatin serving as a prognostic biomarker. Endostatin expression in GECs could be regulated by $\mathrm{pIgA}$, which may provide some clues about the pathogenesis of IgAN.

\section{Acknowledgements}

We would like to express our gratitude to all the patients and healthy controls involved in this study. In addition, Yaling Zhai is extremely grateful to her husband, Dr. Yu Zhang, for his kind suggestion and help in this study.

\section{Statement of Ethics}

The Medical Ethics Committee of the First Affiliated Hospital of Zhengzhou University approved the study protocol, and informed written consent was obtained from each participant. All methods reported here were carried out in accordance with relevant guidelines and regulations of the First Affiliated Hospital of Zhengzhou University.

\section{Conflict of Interest Statement}

The authors declare no competing interests.

\section{Funding Sources}

The work was supported by the National Natural Science Foundation for Youths of China (Grant No. 81600555), China Postdoctoral Science Foundation (Grant No. 2018M640684), National Natural Science Foundation of China (Grant No. 81873611), Science and Technology Innovation Team of Henan (Grant No. 17IRTSTHN020), and Foundation for Leading Personnel of Central Plains of China (Grant No. 194200510006).

\section{Author Contributions}

Yaling Zhai and Zhanzheng Zhao conceived and designed the experiments. Xiaoqing Long, Xingchen Yao, and Xinnian Wang performed experiments. Jingge Gao analyzed the data. Yaling Zhai and Zhanzheng Zhao contributed reagents/materials/analysis tools. Yaling Zhai wrote the paper. All authors read and approved the final manuscript.

\section{Availability of Data and Material}

Raw data used during the current study are available from the corresponding author on reasonable request for noncommercial use.

\section{References}

1 D'amico G. The commonest glomerulonephritis in the world: IgA nephropathy. Q J Med. 1987 Sep;64(245):709-27.

2 Barbour SJ, Espino-Hernandez G, Reich HN, Coppo R, Roberts IS, Feehally J, et al. The MEST score provides earlier risk prediction in $\lg$ A nephropathy. Kidney Int. 2016 Jan;89(1): $167-75$.

3 Working Group of the International Ig ANN, The Renal Pathology Society; Roberts IS, Cook HT, Troyanov S, Alpers CE, Amore A, Barratt. J, et al. The Oxford classification of IgA nephropathy: pathology definitions, correlations, and reproducibility. Kidney Int. 2009 Sep;76(5):546-56.

4 Working Group of the International Ig ANN, The Renal Pathology S; Cattran DC, Troyanov S, Coppo R, Cook HT, Feehally J, Roberts IS, et al. The Oxford classification of IgA nephropathy: rationale, clinicopathological correlations, and classification. Kidney Int. 2009 Sep;76(5):534-45.

5 Suzuki H, Kiryluk K, Novak J, Moldoveanu Z, Herr AB, Renfrow MB, et al. The pathophysiology of IgA nephropathy. J Am Soc Nephrol. 2011 Oct;22(10):1795-803.
6 Kusano T, Takano H, Kang D, Nagahama K, Aoki M, Morita M, et al. Endothelial cell injury in acute and chronic glomerular lesions in patients with $\operatorname{IgA}$ nephropathy. Hum Pathol. 2016 Mar;49:135-44.

7 Zhu L, Shi S, Liu L, Lv J, Zhang H. Increased plasma sVCAM-1 is associated with severity in IgA nephropathy. BMC Nephrol. 2013 Jan $22 ; 14: 21$.

8 Nasri H, Mubarak M. Significance of vasculopathy in IgA nephropathy patients with regard to Oxford classification and immunostaining findings: a single center experience. J Renal Inj Prev. 2013;2(2):41-5.

9 El Karoui K, Hill GS, Karras A, Jacquot C, Moulonguet L, Kourilsky O, et al. A clinicopathologic study of thrombotic microangiopathy in IgA nephropathy. J Am Soc Nephrol. 2012 Jan;23(1):137-48.

10 Zhai YL, Zhu L, Shi SF, Liu LJ, Lv JC, Zhang H. Elevated soluble VEGF receptor sFlt-1 correlates with endothelial injury in IgA nephropathy. PLoS One. 2014;9(7):e101779.
11 Dhanabal M, Ramchandran R, Volk R, Stillman IE, Lombardo M, Iruela-Arispe ML, et al. Endostatin: yeast production, mutants, and antitumor effect in renal cell carcinoma. Cancer Res. 1999 Jan 1;59(1):189-97.

12 Maciel TT, Coutinho EL, Soares D, Achar E, Schor N, Bellini MH. Endostatin, an antiangiogenic protein, is expressed in the unilateral ureteral obstruction mice model. J Nephrol. 2008 Sep-Oct;21(5):753-60.

13 Schips L, Dalpiaz O, Lipsky K, Langner C, Rehak P, Puerstner P, et al. Serum levels of vascular endothelial growth factor (VEGF) and endostatin in renal cell carcinoma patients compared to a control group. Eur Urol. 2007 Jan;51(1):168-74.

14 Marneros AG, Olsen BR. Physiological role of collagen XVIII and endostatin. FASEB J. 2005 May;19(7):716-28.

15 Rehn M, Pihlajaniemi T. Alpha 1(XVIII), a collagen chain with frequent interruptions in the collagenous sequence, a distinct tissue distribution, and homology with type XV collagen. Proc Natl Acad Sci U S A. 1994 May 10; 91(10):4234-8. 
16 Lin CH, Chen J, Zhang Z, Johnson GV, Cooper AJ, Feola J, et al. Endostatin and transglutaminase 2 are involved in fibrosis of the aging kidney. Kidney Int. 2016 Jun;89(6):1281-92.

17 Ruge T, Carlsson AC, Larsson TE, Carrero JJ, Larsson A, Lind L, et al. Endostatin level is associated with kidney injury in the elderly: findings from two community-based cohorts. Am J Nephrol. 2014;40(5):417-24.

18 Arnlov J, Ruge T, Ingelsson E, Larsson A, Sundstrom J, Lind L. Serum endostatin and risk of mortality in the elderly: findings from 2 community-based cohorts. Arterioscler Thromb Vasc Biol. 2013 Nov;33:2689-95.

19 Baradaran A. Renal vascular lesions in IgA nephropathy. J Renal Inj Prev. 2013;2(2):37-

20 Myllymaki J, Syrjanen J, Helin H, Pasternack A, Kattainen A, Mustonen I. Vascular diseases and their risk factors in IgA nephropathy. Nephrol Dial Transplant. 2006 Jul;21:187682.

21 Seppinen L, Pihlajaniemi T. The multiple functions of collagen XVIII in development and disease. Matrix Biol. 2011;30(2):83-92.

22 Carlsson AC, Carrero JJ, Stenvinkel P, Bottai M, Barany P, Larsson A. Arnlov J . Endostatin, cathepsin S, and cathepsin L, and their association with inflammatory markers and mortality in patients undergoing hemodialysis. Blood Purif. 2015;39(4):259-65.
23 Schmidt A, Sommer F, Reiner M, Klotz T, Engelmann U, Addicks K, et al. Differential endostatin binding to bladder, prostate and kidney tumour vessels. BJU Int. 2005 Jan;95(1): 174-9.

24 Chen J, Hamm LL, Kleinpeter MA, Husserl F, Khan IE, Chen CS, et al. Elevated plasma levels of endostatin are associated with chronic kidney disease. Am J Nephrol. 2012;35(4): $335-40$.

25 Robak E, Woźniacka A, Sysa-Jedrzejowska A, Stepień H, Robak T. Circulating angiogenesis inhibitor endostatin and positive endothelial growth regulators in patients with systemic lupus erythematosus. Lupus. 2002;11(6):34855.

26 Feldman AL, Alexander HR Jr, Yang JC, Linehan WM, Eyler RA, Miller MS, et al. Prospective analysis of circulating endostatin levels in patients with renal cell carcinoma. Cancer. 2002 Oct 15;95(8):1637-43.

27 Novak J, Julian BA, Mestecky J, Renfrow MB Glycosylation of IgA1 and pathogenesis of IgA nephropathy. Semin Immunopathol. 2012 May;34(3):365-82.

28 Liu D, Zhang N, Zhang J, Zhao H, Wang X. miR-410 suppresses the expression of interleukin-6 as well as renal fibrosis in the pathogenesis of lupus nephritis. Clin Exp Pharmacol Physiol. 2016 Jun;43(6):616-25.
29 Liu Y, Wang K, Liang X, Li Y, Zhang Y, Zhang $\mathrm{C}$, et al. Complement $\mathrm{C} 3$ produced by macrophages promotes renal fibrosis via IL-17A secretion. Front Immunol. 2018;9:2385.

30 Liu M, Ning X, Li R, Yang Z, Yang X, Sun S, et al. Signalling pathways involved in hypoxia-induced renal fibrosis. J Cell Mol Med. 2017 Jul;21(7):1248-59.

31 Dimou P, Wright RD, Budge KL, Midgley A, Satchell SC, Peak M, et al. The human glomerular endothelial cells are potent pro-inflammatory contributors in an in vitro model of lupus nephritis. Sci Rep. 2019 Jun 6;9:8348.

32 Tanabe K, Maeshima Y, Ichinose K, Kitayama H, Takazawa Y, Hirokoshi K, et al. Endostatin peptide, an inhibitor of angiogenesis, prevents the progression of peritoneal sclerosis in a mouse experimental model. Kidney Int. 2007 Feb;71(3):227-38.

33 Veillard F, Saidi A, Burden RE, Scott CJ, Gillet L, Lecaille F, et al. Cysteine cathepsins S and $\mathrm{L}$ modulate anti-angiogenic activities of human endostatin. J Biol Chem. 2011 Oct 28; 286(43):37158-67.

34 Jobs E, Risérus U, Ingelsson E, Helmersson J, Nerpin E, Jobs M, et al. Serum cathepsin S is associated with serum $\mathrm{C}$-reactive protein and interleukin-6 independently of obesity in elderly men. J Clin Endocrinol Metab. 2010 Sep;95(9):4460-4. 